\section{ACIDENTES MOTOCICLÍSTICOS ENVOLVENDO CRIANÇAS ATENDIDAS PELO SERVIÇO PRÉ-HOSPITALAR DE URGÊNCIA EM GUANAMBI, BAHIA}

\section{MOTORCYCLE ACCIDENTS INVOLVING CHILDREN SERVED BY THE PRE-HOSPITAL EMERGENCY SERVICE IN GUANAMBI, BAHIA}

Adriana Alves Nery ${ }^{1}$ / Beatriz de Almeida Marques ${ }^{2}$ / Deíze Carvalho Pereira / Luzia Célia Batista Soares ${ }^{3, *}$ / Marcela Andrade Rios ${ }^{2}$

\section{INTRODUÇÃO}

Conforme o tempo passou e as necessidades dos homens mudaram, a forma de se transportar também evoluiu. A cada dia os meios de transporte terrestre estão mais modernizados, ganhando assim, maior velocidade, eficiência e conforto, sendo comumente utilizado para a mobilidade diária, seja para o ambiente de trabalho, transporte escolar ou lazer.

Mesmo diante de inúmeros benefícios, este meio de locomoção traz consigo alguns efeitos negativos, dentre eles os acidentes de trânsito. Esses eventos têm etiologia multifatorial não intencional, porém potencialmente evitáveis e representam um problema de saúde pública, devido ao elevado índice de morbimortalidade (SILVA et al., 2017).

Embora os acidentes por transportes terrestres acometam todas as faixas etárias, estes apresentam maior letalidade quando a vítima se encontra entre zero e nove anos de idade e são responsáveis por $95 \%$ dos atendimentos de emergência entre este público (MALTA et al., 2016; SILVA et al., 2017). Além de ter a sua proibição respaldada por lei, o transporte de menores que não tenham condições de cuidar de sua própria segurança consiste em infração gravíssima (BRASIL, 1997).

\section{RESUMO}

Objetivo: Descrever os acidentes motociclísticos e suas vítimas na população de crianças de 0 a 12 anos incompletos, atendidos pelo Serviço de Atendimento Móvel de Urgência-SAMU, nos anos de 2013 e 2017, no município de Guanambi-BA. Métodos: Trata-se de um estudo descritivo e transversal com coleta de dados secundários acerca dos acidentes motociclísticos atendidos pelo Serviço de Atendimento Móvel de Urgência do município Guanambi, nos anos de 2013 e 2017. Foram calculadas frequências absolutas e relativas utilizando o Epi Info, versão 7.0. Resultados: Os acidentes de moto acometem em sua maioria crianças do sexo masculino, maiores de sete anos de idade, estando estas na motocicleta na condição de passageiros. Os acidentes ocorrem principalmente no perímetro urbano, com maior número na quinta-feira e domingo, durante o dia, tendo como meses de maior ocorrência junho e outubro e como mecanismo causador da lesão à colisão com automóvel. A maioria das crianças foi encaminhada para o hospital regional da cidade pela unidade de suporte básico, apresentando em sua maioria lesões do tipo escoriação. Conclusão: A partir dos dados apresentados faz-se necessário a adoção de políticas educativas em creches, escolas e meios de comunicação sobre os risco e complicações de acidentes motociclísticos em crianças.

Palavras-chave: Acidentes de trânsito. Serviços médicos de emergência. Morbimortalidade. Motocicleta.

\section{ABSTRACT}

Objective: To describe motorcycle accidents and their victims in the population aged 0 to 12 years old, attended by the Mobile Emergency Service, in the years 2013 and 2017, in the municipality of Guanambi, Bahia. Methods: This is a descriptive and cross-sectional study with collection of secondary data about motorcycle accidents attended by the Mobile Emergency Service in the municipality of Guanambi, in the years 2013 and 2017. Absolute and relative frequencies were calculated using Epi Info, version 7.0. Results: Most motorcycle accidents affect male children, over seven years of age, being on mortocycle as passengers. Accidents occur mainly in the urban perimeter, with the greatest number of Thursday and Sunday during the day, with the last occurrences being the highest occurrence in June and October and as a mechanism that causes car collision injuries. Most of the children were referred to the regional hospital in the city by the basic support unit, with most injuries of the excoriation type. Conclusion: Based on the data presented, it is necessary to adopt educational policies in daycare centers, schools and th e media on the risks and complications of motorcycle accidents in children.

Keywords: Traffic accidents. Emergency medical services. Morbidity and mortality. Motorcycle.

Submetido em: 08 de nov. 2019

Aceito em: 14 de fev. 2020

${ }^{2}$ Universidade do Estado da Bahia - UNEB, Guanambi, Bahia - Brasil.

${ }^{3}$ Universidade Federal da Bahia, Vitória da Conquista, Bahia - Brasil

*E-mail para correspondência: luziaceliasoares@gmail.com

Rev. ComCiência - jun. 2020, vol. 5, no. 6, p. 45-48/ doi: 10.36112/ issn2595-1890.v5.i6.p45-48 
Neste cenário, a infância é considerada como o período da criação de experiências, desenvolvimento corporal e comportamental, por esta causa, os riscos que as crianças correm no trânsito são diferentes dos adultos, tendo em vista que elas estão em uma fase mais frágil acerca das percepções de perigo (BRASIL, 2012). Além disso, os mecanismos das lesões relacionadas com o trânsito variam de acordo com a resistência corporal, ou pelos múltiplos tipos de impactos que a criança está sujeita nas diferentes faixas etárias.

Independente da dimensão e gravidade do evento ocorrido, o atendimento inicial à saúde necessita de eficiência e agilidade, para isto, o sistema público de saúde conta com o Serviço de Atendimento Móvel de Urgência (SAMU), este serviço de cuidado pré-hospitalar objetiva promover a preservação da vida, redução de sequelas, além de ofertar um transporte adequado, rápido e resolutivo às vítimas acometidas por agravos à saúde de qualquer natureza (COSTA; MIRANDA; SOUZA, 2013).

Com base no exposto, o presente estudo objetivou descrever os acidentes motociclísticos e suas vítimas na população de crianças de 0 a 12 anos incompletos, atendidos pelo SAMU nos anos de 2013 e 2017, no município de Guanambi-BA, quanto às características da vítima, do atendimento, do acidente e das lesões sofridas.

\section{MATERIAIS E MÉTODOS}

Trata-se de um estudo descritivo e transversal com coleta de dados secundários acerca dos acidentes motociclísticos e suas vítimas na população de crianças de 0 a 12 anos incompletos, atendidas pelo Serviço de
Atendimento Móvel de Urgência do município Guanambi, localizado no alto sertão da Bahia, nos anos de 2013 e 2017.

A população do estudo foi composta por todos os prontuários dos indivíduos de 0 a 12 anos incompletos que sofreram acidentes motociclísticos e foram socorridos por equipes do SAMU do município de Guanambi, entre os anos de 2013 e 2017, os quais foram selecionados manualmente pelas pesquisadoras.

Utilizou-se como base para definição do conceito de criança abordada pelo Estatuto da Criança e do Adolescente - ECA, que define criança como a pessoa até doze anos de idade incompletos (BRASIL, 1990).

Para coleta de dados utilizou-se um formulário elaborado pelas pesquisadoras onde continham variáveis relacionadas à vítima como: sexo, faixa etária e posição na motocicleta; quanto ao atendimento: mês, dia, ano, turno do atendimento, procedimentos realizados, encaminhamentos e o tipo de unidade utilizada; com relação ao acidente: local de ocorrência, outra vítima envolvida, tipo de veículo envolvido, uso de capacete, evento relacionado ao trabalho e características dos óbitos. No que concerne às lesões sofridas foram estudadas as variáveis: tipos e locais das lesões.

Os dados coletados foram transcritos para o programa Microsoft Office Excel 2010, posteriormente foram analisados através do programa estatístico Epi Info ${ }^{\mathrm{TM}}$ versão 7.0 (Centers for Disease Con-trol and Prevention, Atlanta, Estados Unidos), sendo realizados cálculos de frequência absoluta e relativa para as variáveis categóricas.

O estudo teve o projeto submetido e aprovado pelo Comitê de Ética em Pesquisa - CEP da Universidade Estadual do Sudoeste da Bahia
(UESB), Campus Jequié, sob CAAE $\mathrm{n}^{\circ}$ 47391615.5.1001.0055 e parecer $n^{\circ}$ 1.378.843, respeitando assim, todos os preceitos éticos que regem as pesquisas envolvendo seres humanos.

\section{RESULTADOS E DISCUSSÃO}

O SAMU de Guanambi/BA registrou 3.290 acidentes motociclísticos entre os anos 2013 a 2017. Destes, 61 ocorrências envolveram crianças menores de 12 anos.

No que diz respeito à distribuição dos acidentes de acordo os anos de ocorrência, o ano de maior incidência foi 2014 com 15 casos $(24,6 \%)$ e o ano de menor frequência foi $2013 \mathrm{com}$ oito $(13,1 \%)$ acidentes envolvendo crianças.

De acordo a avaliação sociodemográfica, o sexo mais prevalente entre as crianças acidentadas foi $\mathrm{o}$ masculino $(\mathrm{n}=33 ; 54,1 \%)$, sendo 28 vítimas $(45,9 \%)$ do sexo feminino. Quanto à idade, as maiores de 7 anos $(n=41 ; 67,2 \%)$ representaram o maior quantitativo de crianças vitimadas, as menores de 7 anos registraram 20 ocorrências de acidentes de moto $(32,8 \%)$. Ressalta-se que a divisão da idade deuse a partir da legislação vigente na qual os indivíduos menores de setes anos não podem se locomover em motocicletas (BRASIL, 1997).

A predominância do sexo masculino deve-se provavelmente às questões socioculturais, pois a liberdade concedida à população masculina é mais precoce quando comparada a feminina, somado a isso, eles tem menor supervisão direta dos responsáveis e maior vulnerabilidade ao conduzir veículos de forma arriscada, ou brincar perto de ruas ou rodovias (GORIOS, 2014).

Segundo o tipo de vítima, a categoria de passageiro foi a que apre- 
sentou o maior número de casos $(n=40 ; 65,6 \%)$, todavia, é interessante relatar que das crianças envolvidas nos acidentes de moto descritos neste estudo, cinco delas estavam na condição de condutores.

A respeito disso, o Código de Trânsito Brasileiro - CTB (Lei 9.503/97), que é a lei que estabelece as normas do trânsito no Brasil, determina que, para se habilitar como condutor é necessário ser penalmente imputável (ter 18 anos completos), saber ler e escrever, possuir documento de identidade e possuir Cadastro de Pessoa Física - CPF (BRASIL, 1997).

No que se refere às características relacionadas ao acidente, a maioria dos casos ocorreram no período da tarde $(n=30 ; 49,2 \%)$, seguidos pelo turno matutino $(\mathrm{n}=17 ; 27,9 \%)$, sendo que o período da madrugada foi o de menor incidência $(n=2 ; 3,3 \%)$. Tal fato pode ser justificado devido à locomoção destas crianças para a escola, além disso, percebe-se que a madrugada obteve menores ocorrências, sendo este turno o que as crianças mais permanecem em suas residências.

$\mathrm{O}$ dia da semana que registrou o maior número de acidentes foi a quinta-feira $(n=14 ; 22,9 \%)$ seguida pelo domingo $(n=13 ; 21,3 \%)$. Nos dias da semana as crianças utilizam com maior frequência os meios de transporte como locomoção para as atividades educativas e nos finais de semana, estes utilizam com maior proporção tal veículo devido acompanharem seus pais em atividades comemorativas, lúdicas, etc.

Nos meses de junho e outubro foram registrados os maiores números de ocorrências com 7 casos registrados em ambos $(11,5 \%)$. Este achado pode ser justificado devido às festividades do São João, início das férias escolares em junho e pela comemoração do dia das crianças do mês de outubro, mas entende-se que outros fatores não elucidados podem contribuir para a sazonalidade destes acidentes (Tabela 1).

De acordo o local e ocorrência do acidente, a via pública urbana $(n=40 ; 65,6 \%)$ registrou o maior quantitativo dentre os casos. Isso se explica devido ao aumento de veículos circulantes nas capitais e adjacências, que promove por sua vez, uma maior ocorrência de acidentes (CAVALCANTE et al., 2015).

Segundo o mecanismo desencadeador da lesão, a principal causa registrada para os acidentes foi à colisão com automóvel ( $n=24 ; 39,4 \%)$. Estudo aponta que a cinemática do trauma define o grau de gravidade dos acidentes, sendo que, o acidente mostra-se mais grave quando há acentuada transferência de energia cinética, que é o caso da colisão entre dois veículos (ALMEIDA et al., 2013).

Referente ao uso do capacete, este foi observado em 11 ocorrências $(18,0 \%)$, com destaque para o subregistro desta variável em 41 casos $(67,2 \%)$. Sobre este achado, o CTB, através do Artigo 55, discorre sobre a utilização dos equipamentos de segurança por condutores e passageiros de motocicletas, sendo que o capacete deve estar apropriado para uso com ajuste de fivela, faixa refletiva, tamanho adequado à anatomia do crânio, viseira e selo do Instituto Nacional de Metrologia, Qualidade e Tecnologia (Inmetro), o Artigo também cita o uso de vestuário de proteção de acordo com as especificações do Conselho Nacional de Trânsito (CONTRAN) (BRASIL, 1997).

Ressalta-se sobre a importância do devido preenchimento das informações referentes aos acidentes motociclísticos, pois as mesmas servem como subsídios para elaboração de medidas preventivas e de combate para tal agravo.

No referente estudo, 54 crianças $(88,5 \%)$ apresentaram algum tipo lesão, sendo mais frequente a escoriação $(n=43 ; 70,5 \%)$. A ocorrência deste ferimento é favorecida pelo contato direto da vítima com o solo, o que promove a perda de continuidade da pele, levando ao aparecimento de uma escoriação (RODRIGUES et al., 2014).

No que diz respeito à assistência prestada as vítimas, os procedimentos mais realizados foram: curativos $(n=23 ; 37,7 \%)$, imobilização $(n=22$; $36,1 \%)$, punção venosa $(n=13 ; 21,3 \%)$ e a reposição volêmica $(n=12 ; 19,7 \%)$, o que reforça a importância do serviço de atendimento móvel que chega rápido ao local do acidente com inicio precoce dos primeiros cuidados.

Segundo o encaminhamento das vítimas, estas foram transportadas principalmente para o hospital público do município $(n=47 ; 77,0 \%)$. A Unidade de Suporte Básico (USB) foi responsável por 39 atendimentos $(63,9 \%)$. Este fato pode ser explicado pela complexidade do acidente, fragilidade do organismo das crianças, extensão das lesões, ou pela Unidade de saúde servir como local de referência para tais agravos.

\section{CONCLUSÃO}

O presente estudo revelou que os acidentes de moto envolvendo crianças acometem em sua maioria o sexo masculino, as crianças maiores de sete anos de idade, estando estas na motocicleta na condição de passageiros. A respeito das características do acidente, a maioria ocorreu no perímetro urbano, sendo o mecanismo causador da lesão a colisão com automóvel, ocorrendo estes acidentes em maior 
número na quinta-feira e domingo, durante o dia, tendo como meses de maior ocorrência junho e outubro. A maioria das crianças foi encaminhada para o hospital regional da cidade, pela unidade de suporte básico, apresentando em sua maioria lesões do tipo escoriação.

Tabela 1 - Características dos acidentes com crianças menores de 12 anos, envolvendo motocicletas, atendidos pelo Serviço de Atendimento Móvel de Urgência, do município de Guanambi/BA, nos anos de 2013 a 2017.

\begin{tabular}{|c|c|c|}
\hline Variáveis & $\mathbf{N}$ & $\%$ \\
\hline \multicolumn{3}{|l|}{ Local do acidente } \\
\hline Via pública urbana & 40 & 65,6 \\
\hline Via rural & 10 & 16,4 \\
\hline Rodovia & 10 & 16,4 \\
\hline SI & 1 & 1,6 \\
\hline \multicolumn{3}{|l|}{ Tipo de vítima } \\
\hline Condutor & 5 & 8,2 \\
\hline Passageiro & 40 & 65,6 \\
\hline SI & 16 & 26,2 \\
\hline \multicolumn{3}{|l|}{ Encaminhamento } \\
\hline Conduzido ao hospital & 47 & 77 \\
\hline Conduzido a UPA & 5 & 8,3 \\
\hline $\begin{array}{l}\text { Atendido e deixado no } \\
\text { local }\end{array}$ & 9 & 14,7 \\
\hline \multicolumn{3}{|l|}{ Tipo de Unidade } \\
\hline USB & 39 & 63,9 \\
\hline USA & 16 & 26,2 \\
\hline Motolância & 1 & 1,6 \\
\hline Mais de uma de unidade & 5 & 8,2 \\
\hline \multicolumn{3}{|l|}{ Outra parte envolvida } \\
\hline Automóvel & 24 & 39,4 \\
\hline Queda de moto & 22 & 36,1 \\
\hline Motocicleta & 11 & 18 \\
\hline Caminhão & 2 & 3,3 \\
\hline Objeto fixo & 1 & 1,6 \\
\hline SI & 1 & 1,6 \\
\hline \multicolumn{3}{|l|}{ Procedimentos } \\
\hline Curativo & 23 & 37,7 \\
\hline Imobilização & 22 & 36,1 \\
\hline Punção venosa & 13 & 21,3 \\
\hline Reposição volêmica & 12 & 19,7 \\
\hline \multicolumn{3}{|l|}{ Uso do capacete } \\
\hline Sim & 11 & 18 \\
\hline Não & 9 & 14,8 \\
\hline SI & 41 & 67,2 \\
\hline \multicolumn{3}{|l|}{ Lesão } \\
\hline Sim & 54 & 88,5 \\
\hline Não & 4 & 6,6 \\
\hline SI & 3 & 4,9 \\
\hline \multicolumn{3}{|l|}{ Lesão principal } \\
\hline Escoriação & 43 & 70,5 \\
\hline
\end{tabular}

*SI Sem Informação

Fonte: Serviço de Atendimento Móvel de Urgência de Guanambi- Bahia, 2018.

É de extrema importância a adoção de políticas educativas em creches, escolas e meios de comunicação sobre os risco e complicações de acidentes motociclísticos em crianças, bem como a sensibilização a respeito da utilização de equipamentos de segurança. Associado a isso, os órgãos fiscalizadores devem intensificar as intervenções tanto em vias públicas urbanas, como também nas rodovias brasileiras.

Deve-se ressaltar ainda a necessidade de uma maior qualidade dos registros dos profissionais de saúde que realizam o atendimento as vítimas, isso reflete na urgência de capacitações educacionais sobre a importância e eficácia do bom preenchimento das fichas.

\section{REFERÊNCIAS}

ALMEIDA, R. L. F. et al. Via, homem e veículo: fatores de risco associados à gravidade dos acidentes de trânsito. Revista de Saúde Pública, v. 47, p. 718-731, 2013.

BRASIL. Lei n ${ }^{\circ}$ 9.503, de 23 de setembro de 1997. Institui o Código de Trânsito Brasileiro. Diário Oficial da União 23 set 1997. Disponível em: < http://www.planalto.gov.br/ccivil_03/1 eis/19503.htm> Acesso em: 10 out 2019.

BRASIL. Ministério da Educação. Secretaria de Educação Básica. Brinquedos e brincadeiras de creches: manual de orientação pedagógica. Brasília, 2012.

BRASIL. Lei no 8.069, de 13 de julho de 1990. Dispõe sobre o Estatuto da Criança e do Adolescente e dá outras providências. Diário Oficial [da] República Federativa do Brasil, Brasília, DF, 16 jul. 1990. Disponível em: < http:/ /www.p lanalto. gov.br/ ccivil_ 03/ leis/18069.htm >. Acesso em: 10 out. 2019.

CAVALCANTE, A. K. C. B. et al.Perfil dos acidentes de trânsito atendidos por serviço pré-hospitalar móvel.RevistBaiana de Enfer, v. 29, n. 2, p. 135-145, 2015.
COSTA, P.C.; MIRANDA, J.O.F.; SOUZA, K.A.O. Pediatric prehospital assistance conducted by the mobile emergency care service (Samu). J. Res.: Fundam. Care; v. 5, n. 4, p. 614-621, 2013.

GORIOS, C. et al., Acidentes de transporte de crianças e adolescentes em serviço de emergência de hospital de ensino, Zona Sul da cidade de São Paulo. Revista Brasileira de Ortopedia, v. 49, n. 4, p. 391-395, 2014.

MALTA, D. C. et al. A ocorrência de causas externas na infância em serviços de urgência: aspectos epidemiológicos, Brasil, 2014. Ciência \& Saúde Coletiva, v. 21 , n. 12 , p. $3729-3744$, 2016.

RODRIGUES, A. P. B. et al. Caracterização dos acidentes motociclísticos atendidos pelo serviço de atendimento móvel de urgência. Rev Enferm UFPE, v. 3, n. 3, p. 73-78, 2014.

SILVA, L. S. R. et al. Mortalidade infantil relacionada a diversos tipos de acidentes por causas externas. Rev enferm UFPE on line, v. 11, supl. 5, p. 2098-2105, 2017. 